Check for updates

Cite this: RSC Adv., 2019, 9, 21075

Received 25th April 2019

Accepted 1st July 2019

DOI: 10.1039/c9ra03077h

rsc.li/rsc-advances

\title{
Preparation of a poly(acrylic acid) based hydrogel with fast adsorption rate and high adsorption capacity for the removal of cationic dyes $\uparrow$
}

\author{
Zhenyu Yuan, ${ }^{a}$ Jie Wang, (D) *a Yiming Wang, ${ }^{\mathrm{b}}$ Qian Liu, ${ }^{\mathrm{b}}$ Yujie Zhong, ${ }^{\mathrm{a}}$ Yu Wang, ${ }^{\mathrm{a}}$ \\ Li Li, (iD a Stephen F. Lincoln ${ }^{c}$ and Xuhong Guo (D) ad
}

\begin{abstract}
A biocompatible Dex-MA/PAA hydrogel was prepared through copolymerization of glycidyl methacrylate substituted dextran (Dex-MA) with acrylic acid (AA), which was applied as the adsorbent to remove cationic dyes from aqueous solutions. Dex-MA/PAA hydrogel presented a fast adsorption rate and the removal efficiency of Methylene Blue (MB) and Crystal Violet (CV) reached $93.9 \%$ and $86.4 \%$, respectively within one minute at an initial concentration of $50 \mathrm{mg} \mathrm{L}^{-1}$. The adsorption equilibrium data fitted the Sips isotherm model well with high adsorption capacities of $1994 \mathrm{mg} \mathrm{g}^{-1}$ for MB and $2390 \mathrm{mg} \mathrm{g}^{-1}$ for $\mathrm{CV}$. Besides, dye adsorption occurred efficiently over the $\mathrm{pH}$ range 3-10 and the temperature range 20$60{ }^{\circ} \mathrm{C}$. Moreover, the removal efficiencies for MB and CV were still $>95 \%$ even after five adsorption/ desorption cycles which indicates the robust nature of the Dex-MA/PAA hydrogel and its potential as an eco-friendly adsorbent for water treatment.
\end{abstract}

\section{Introduction}

The growing use of dyes in cosmetics, papermaking, medicine and food has caused serious environmental pollution, especially in water sources and aquatic ecosystems. ${ }^{\mathbf{1 , 2}}$ Most of these dyes are aromatic compounds which exhibit varying degrees of toxicity and are not readily degraded by light, heat, oxidizing agents, and biological agents. ${ }^{3}$ Consequently, it is necessary to remove these dyes from the polluted water generated during their usage.

A series of physicochemical techniques, such as adsorption, ${ }^{4}$ photocatalytic degradation, ${ }^{5}$ electro-kinetic coagulation, ${ }^{6}$ precipitation, ${ }^{7}$ membrane filtration, ${ }^{8}$ and flocculation, ${ }^{9}$ have been developed for the removal of dyes from waste water. Of these methods, adsorption emerges as a superior industrial water treatment method due to the simplicity of design, low cost, stability and reusability of the adsorbents. ${ }^{10,11}$ In some cases the adsorbent is biodegradable. ${ }^{\mathbf{1 2}}$

In designing dye adsorbents, we are particularly interested in hydrogels which are three-dimensional hydrophilic polymer

${ }^{a}$ State Key Laboratory of Chemical Engineering, East China University of Science and Technology, 200237 Shanghai, P. R. China. E-mail: jiewang2010@ecust.edu.cn ${ }^{b}$ Department of Chemical Engineering, Delft University of Technology, $2629 \mathrm{HZ}$ Delft, The Netherlands

${ }^{c}$ School of Physical Sciences, University of Adelaide, Adelaide, SA 5005, Australia ${ }^{d}$ Engineering Research Center of Materials Chemical Engineering of Xinjiang Bingtuan, Shihezi University, 832000 Xinjiang, P. R. China

$\dagger$ Electronic supplementary information (ESI) available. See DOI: 10.1039/c9ra03077h networks which absorb large amounts of water. ${ }^{\mathbf{1 3}}$ These characteristics, in combination with the substitution of appropriate functional groups to give the required adsorbent properties, render hydrogels versatile adsorbents which earlier studies have shown to be readily regenerated for reuse. Thus, substituent hydroxyl and carboxylate groups can selectively interact with cationic dyes or metal ions at appropriate pH values. ${ }^{\mathbf{1 4}}$

Natural polysaccharides are attractive materials for adsorbent hydrogel construction for water purification because of their ready availability and biodegradability. Chitosan, ${ }^{15}$ cellulose, ${ }^{16}$ starch $^{17}$ and guar gum ${ }^{18}$ have been widely applied for construction of adsorbents and shows good adsorption properties, such as those combined with amino, carboxyl, cyclodextrin and other inorganic composition. Among various natural polysaccharides, dextran is an important starting material for new functional materials with promising properties. ${ }^{19}$ Due to its common solubility, biocompatibility, and biodegradability, dextran is already successfully applied in the medical and biomedical field, ${ }^{20-22}$ however, the applications in adsorbents were seldom reported. Here, we synthesized a hydrogel adsorbent based on dextran. The numerous hydroxyl groups of dextran render it amenable to substitution with other groups according to the requirements of the substituted product. Accordingly, we substituted dextran through reaction with glycidyl methacrylate (GMA) to produce the double bond modified dextran (Dex-MA), which has been used for building hydrogel or micro-gels and recently applied in the area of hemostatic agent and micro carriers. ${ }^{23}$ Then Dex-MA was copolymerized with acrylic acid (AA) to give the Dex-MA/PAA hydrogel. The carboxylic group can interact with various 
cationic pollutants, especially the cationic dyes and the regeneration process can be easily realized by changing the solution $\mathrm{pH}$.

The structure and thermal behavior of Dex-MA/PAA were characterized by ${ }^{1} \mathrm{H}$ NMR, FT-IR, TGA/DTG and SEM. The ability of Dex-MA/PAA to act as an adsorbent for the removal of the cationic dyes, Methylene Blue (MB) and Crystal Violet (CV) (Fig. 1) from aqueous solution was characterized through thermodynamic and kinetic studies. The effects of $\mathrm{pH}$ variation and sodium chloride concentration on the dye adsorption process were also determined. Overall, Dex-MA/PAA showed a rapid dye adsorption rate and a high absorption capacity which remained higher than 95\% after five-adsorption/desorption-cycles.

\section{Materials and methods}

\subsection{Materials}

All chemicals, including dextran with an average molecular weight of $150 \mathrm{kDa}$, were purchased from Sigma-Aldrich. Aqueous solutions of Methylene Blue and Crystal Violet were prepared using deionized water. The $\mathrm{pH}$ of the solutions was adjusted with $0.1 \mathrm{M}$ sodium hydroxide and $0.1 \mathrm{M}$ hydrochloric acid.

\subsection{Synthesis of glycidyl methacrylate modified dextran (Dex-MA)}

The preparation of Dex-MA followed literature methods. ${ }^{24,25}$ Dextran (10.0 g, $0.067 \mathrm{mmol})$ was dissolved in DMSO (90 mL) with stirring after which 4-dimethylaminopyridine (DMAP) $(2.0 \mathrm{~g}, 16.37 \mathrm{mmol})$ and glycidyl methacrylate (GMA) (1.58 g, $11.11 \mathrm{mmol}$ ) were added and stirring was continued at room temperature for $24 \mathrm{~h}$. The resulting viscous solution was transferred into a dialysis tube (molecular weight cut off $=$ 8000-12 $000 \mathrm{Da}$ ) and dialyzed against deionized water for two days to remove DMSO and unreacted material. The resulting aqueous solution was lyophilized to obtain a white product. The $400 \mathrm{MHz}{ }^{1} \mathrm{H}$ NMR spectrum of a $\mathrm{D}_{2} \mathrm{O}$ solution exhibited resonances at 6.25, $5.80\left(2 \mathrm{H}, \mathrm{CH}_{2}=\mathrm{C}\right), 5.35,5.01$ (anomeric proton), $1.99\left(3 \mathrm{H},-\mathrm{CH}_{3}\right) \delta$, ppm.

\subsection{Synthesis of the Dex-MA/PAA hydrogel}

To prepare the Dex-MA/PAA hydrogel, $0.5 \mathrm{~g}$ Dex-MA and $2 \mathrm{~g}$ AA were dissolved in $20 \mathrm{~mL}$ phosphate buffer (0.01 M, pH 8.0) followed by the addition of $10 \mathrm{mg}$ of ammonium

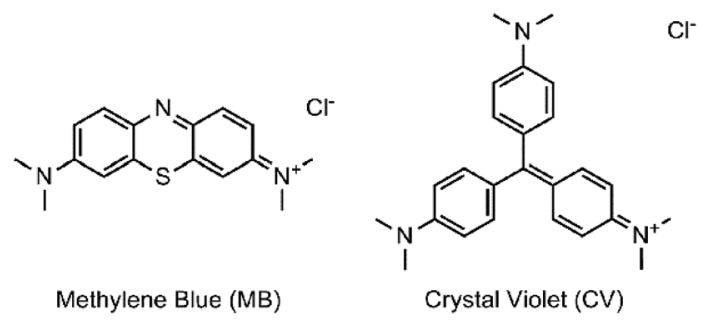

Fig. 1 Structure of Methylene Blue (MB) and Crystal Violet (CV). peroxydisulfate (APS) as initiator. This mixture was reacted at $70{ }^{\circ} \mathrm{C}$ under nitrogen for $2 \mathrm{~h}$ to form the Dex-MA/PAA hydrogel which was then cooled to room temperature and rinsed with deionized water to remove unreacted monomers and other impurities. Then the Dex-MA/PAA hydrogel were immersed in 0.1 M sodium hydroxide followed by washing with a large amount of water. Finally, the hydrogel was freeze dried, ground and stored at room temperature in a dry environment.

\subsection{Characterization}

${ }^{1} \mathrm{H}$ NMR spectra were obtained in $\mathrm{D}_{2} \mathrm{O}$ solutions using a Bruker Avance DRX-400 at room temperature. Fourier transform infrared (FT-IR) spectra were obtained from $\mathrm{KBr}$ pellets on a NICOLET 6700 spectrometer in transmittance mode in the range 400-4000 $\mathrm{cm}^{-1}$. The network morphology of the hydrogel was observed using a SEM-JEOL6010LA scanning electron microscope. Thermogravimetric analysis (TGA) and derivative thermogravimetric analysis (DTG) were conducted on a Mettler Toledo TGA/SDTA851 instrument in the temperature range 20 to $1000{ }^{\circ} \mathrm{C}$ with a ramp of $10{ }^{\circ} \mathrm{C} \mathrm{min}^{-1}$ under a $\mathrm{N}_{2}$ flow (100 $\mathrm{mL} \min ^{-1}$ ).

\subsection{Swelling study}

To measure the hydrogel swelling ratio, $100 \mathrm{mg}$ of freeze-dried Dex-MA/PAA hydrogel was immersed in $200 \mathrm{~mL}$ deionized water. After the swelling hydrogel reached equilibrium, it was removed from the deionized water, residual surface water was removed and it was weighed. The swelling ratio (SR) was calculated through eqn (1):

$$
\mathrm{SR}=\frac{m_{\mathrm{s}}-m_{\mathrm{d}}}{m_{\mathrm{d}}}
$$

where $m_{\mathrm{s}}(\mathrm{g})$ and $m_{\mathrm{d}}(\mathrm{g})$ are the weights of the Dex-MA/PAA hydrogel in the swollen and dry states, respectively. The swelling ratio was calculated to be 168 .

\subsection{Determination of active carboxyl group content}

The active carboxyl group content of the Dex-MA/PAA hydrogel was determined by titration. ${ }^{26,27}$ A $40 \mathrm{mg}$ sample of the hydrogel was added to $200 \mathrm{~mL}$ hydrochloric acid $(10 \mathrm{mM})$ and stirred overnight to convert the sodium salt to the carboxylic acid form. After filtering, $50 \mathrm{~mL}$ of the filtrate was titrated with sodium hydroxide $(5 \mathrm{mM})$. The titration was carried out in triplicate. The Dex-MA/PAA hydrogel carboxyl group content, $C(\mathrm{mmol}$ $\mathrm{g}^{-1}$ ), was calculated through eqn (2):

$$
C=\frac{C_{\mathrm{i}}-C_{\mathrm{f}}}{m} V
$$

where $C_{\mathrm{i}}\left(\mathrm{mol} \mathrm{L}^{-1}\right), C_{\mathrm{f}}\left(\mathrm{mol} \mathrm{L}^{-1}\right)$ and $V(\mathrm{~mL})$ are the initial and final concentrations of the hydrochloric acid solution, respectively, $V(\mathrm{~mL})$ is its volume, and $m(\mathrm{~g})$ is the mass of Dex-MA/PAA. The carboxyl group content was calculated to be $6.21 \mathrm{mmol} \mathrm{g}^{-1}$. 


\subsection{Determination of $\mathrm{pH}$ at the point of zero charge for Dex- MA/PAA ( pH $_{\text {PZC }}$ )}

The $\mathrm{pH}$ at which Dex-MA/PAA was uncharged, the point of zero charge, $\mathrm{pH}_{\mathrm{PZC}}$, was determined by the $\mathrm{pH}$-drift method. ${ }^{28}$ Nitrogen was bubbled through $50 \mathrm{~mL}$ of each of nine sodium chloride solutions $(10 \mathrm{mM})$ at room temperature for several minutes to expel dissolved $\mathrm{CO}_{2}$. The $\mathrm{pH}$ of the solutions was adjusted to nine different initial values $\left(\mathrm{pH}_{\text {initial }}\right)$ in the range 2.0-10 with $0.1 \mathrm{M}$ hydrochloric acid or $0.1 \mathrm{M}$ sodium hydroxide. Subsequently, $50 \mathrm{mg}$ of Dex-MA/PAA was added to each solution which was stirred for 4 hours at $250 \mathrm{rpm}$. The solutions were then filtered and the final $\mathrm{pH}\left(\mathrm{pH}_{\text {final }}\right)$ of each filtrate was measured and the $\mathrm{pH}_{\text {final }}-\mathrm{pH}_{\text {initial }}$ values were plotted against $\mathrm{pH}_{\text {initial }}$ of the solutions. The $\mathrm{pH}_{\mathrm{PZC}}$ (6.6 for Dex-MA/PAA) was the point at which the value of $\mathrm{pH}_{\text {final }}-\mathrm{pH}_{\text {initial }}$ is zero.

\subsection{Dye adsorption experiments}

All dye adsorption experiments were initiated by adding $20 \mathrm{mg}$ of Dex-MA/PAA to $20 \mathrm{~mL}$ dye solutions at a selected $\mathrm{pH}_{\text {initial }}$ followed by stirring at $200 \mathrm{rpm}$ for $3 \mathrm{~h}$. The mixture was then filtered and the residual dye content was determined by UV-vis absorption at $664 \mathrm{~nm}$ for $\mathrm{MB}$ and $590 \mathrm{~nm}$ for CV using a UV1800, SHIMADZU spectrophotometer.

The influence of the variation of $\mathrm{pH}(2-10)$, salt concentration $(0-400 \mathrm{mM})$, temperature $\left(20-60^{\circ} \mathrm{C}\right)$ and contact time $(0-60$ min) on the adsorption of $\mathrm{MB}$ and $\mathrm{CV}$ were investigated at an initial dye concentration of $50 \mathrm{mg} \mathrm{mL} \mathrm{m}^{-1}$. The $\mathrm{pH}$ of each dye solution was adjusted with either $0.1 \mathrm{M}$ hydrochloric acid or $0.1 \mathrm{M}$ sodium hydroxide. The salt concentration was adjusted by adding sodium chloride into the dye solution. The influence of initial dye concentrations (MB 20-2200 $\mathrm{mg} \mathrm{L}^{-1}$, CV 50-2600 mg $\mathrm{mL}^{-1}$ ) on adsorption was studied at $20^{\circ} \mathrm{C}$ and $\mathrm{pH}$ 8.0. In kinetic studies, the mixture was immediately stirred and $3 \mathrm{~mL}$ of suspension were taken at specific intervals via syringe and filtrated immediately by a $1 \mu \mathrm{m}$ filter. All experiments were performed in triplicate. The dye removal efficiency $(R \%)$ was calculated through eqn (3):

$$
R \%=\frac{C_{0}-C_{\mathrm{t}}}{C_{0}} \times 100 \%
$$

where $C_{0}$ and $C_{\mathrm{t}}$ are the initial and final concentration of dye (mg L ${ }^{-1}$ ), respectively.

The adsorption capacity $\left(q_{\mathrm{e}}, \mathrm{mg} \mathrm{g}^{-1}\right)$ of Dex-MA/PAA was calculated through eqn (4):

$$
q_{\mathrm{e}}=\frac{C_{0}-C_{\mathrm{e}}}{m} V
$$

where $C_{0}$ and $C_{\mathrm{e}}$ are the initial and equilibrium dye concentration $\left(\mathrm{mg} \mathrm{L}^{-1}\right)$, respectively. $V(\mathrm{~L})$ is the volume of dye solution and $m(\mathrm{~g})$ is the weight of Dex-MA/PAA.

\subsection{Regeneration tests}

A sample of $40 \mathrm{mg}$ of dry Dex-MA/PAA was added to $40 \mathrm{~mL}$ of MB or CV solution $\left(50 \mathrm{mg} \mathrm{L}^{-1}\right)$ at an initial of $\mathrm{pH} 8.0$, and the mixture was stirred for $3 \mathrm{~h}$ at $20{ }^{\circ} \mathrm{C}$ to obtain dye saturation of the hydrogel. Then, Dex-MA/PAA was separated from the mixture and immersed in $50 \mathrm{~mL}$ hydrochloric acid $(0.1 \mathrm{M})$ for $3 \mathrm{~h}$ to release the adsorbed dyes. The separated Dex-MA/PAA was washed with deionized water and the adsorption sites were reactivated by soaking in $50 \mathrm{~mL}$ of $0.1 \mathrm{M}$ sodium hydroxide for 1 hour. It was then separated again, washed with deionized water and freeze dried before repeating the above described dye adsorption experiment. This adsorption/desorption cycle was repeated five times for each dye.

\section{Results and discussion}

\subsection{Characterization of Dex-MA and the Dex-MA/PAA hydrogel}

The preparations of Dex-MA and Dex-MA/PAA hydrogel are shown in Scheme 1. The chemical structure of Dex-MA was confirmed by FT-IR and the degree of substitution (DS) of the methacrylate group on dextran was calculated to be $10.5 \%$ from its ${ }^{1} \mathrm{H}$ NMR spectrum (Fig. S1 $\dagger$ ). ${ }^{29}$ The FT-IR spectra of dextran, Dex-MA and Dex-MA/PAA hydrogel in Fig. 2 show the progressive changes as the synthesis proceeded. After soaking the DexMA/PAA hydrogel in sodium hydroxide solution, the peak at $1571 \mathrm{~cm}^{-1}$ arising from the deprotonation of the Dex-MA/PAA acrylic acid groups appeared together with that from methacrylate (from the Dex-MA $(\mathrm{C}=\mathrm{O})$ component) at $1721 \mathrm{~cm}^{-1}$ in Fig. $2 \mathrm{a}^{30}$ The double bond peak at $813 \mathrm{~cm}^{-1}$ in the Dex-MA spectrum was absent from the Dex-MA/PAA spectrum after copolymerization with acrylic acid to give the hydrogel. The effect of degree of substitution and AA content were studied before systematically studying the adsorption properties of hydrogels, which was shown in Fig. S3 and S4. $\dagger$

The thermostabilities of Dex-MA and Dex-MA/PAA were analyzed by TGA/DTG. As shown in Fig. 3a, the loss of bonded water in Dex-MA leads to a very small weight loss at $\sim 100{ }^{\circ} \mathrm{C}$. When the temperature was increased to $\sim 300^{\circ} \mathrm{C}$, Dex-MA began to decompose, leading to $72 \%$ loss of weight when the temperature increased to $450{ }^{\circ} \mathrm{C}$. For the Dex-MA/PAA hydrogel, multiple thermal decomposition regions were observed. The initial weight loss (about $10.1 \%$ ) below $160{ }^{\circ} \mathrm{C}$ was ascribed to water loss. The second weight loss of $21.5 \%$ occurred between $160^{\circ} \mathrm{C}$ and $380^{\circ} \mathrm{C}$ and was attributed to anhydride formation by PAA chains and the decomposition of the Dex-MA components. The third weight loss of $25.8 \%$ occurred between $380{ }^{\circ} \mathrm{C}$ and $554{ }^{\circ} \mathrm{C}$ and was assigned to thermal degradation of the polyacrylic anhydride. The final weight loss of $29.24 \%$ occurred as the residual Dex-MA/PAA hydrogel decomposed above $720{ }^{\circ} \mathrm{C} .{ }^{4}$ The weight losses are clearly seen in the DTG curves in Fig. $3 \mathrm{~b}$.

The SEM images of the Dex-MA/PAA hydrogel showed a three-dimensional network with large pore sizes in the range of $100-1000 \mu \mathrm{m}$ as seen in Fig. 4a. In aqueous solution, these large pore sizes facilitate the exchange of water between the interior and exterior of the hydrogel.

\subsection{Effect of $\mathrm{pH}$ on dye adsorption}

The active carboxyl group content of the Dex-MA/PAA hydrogel adsorbent was found to be $6.21 \mathrm{mmol} \mathrm{g}^{-1}$ and the mass ratio between Dex-MA and PAA was calculated to be 1.23. Given this 
(a)

(b)
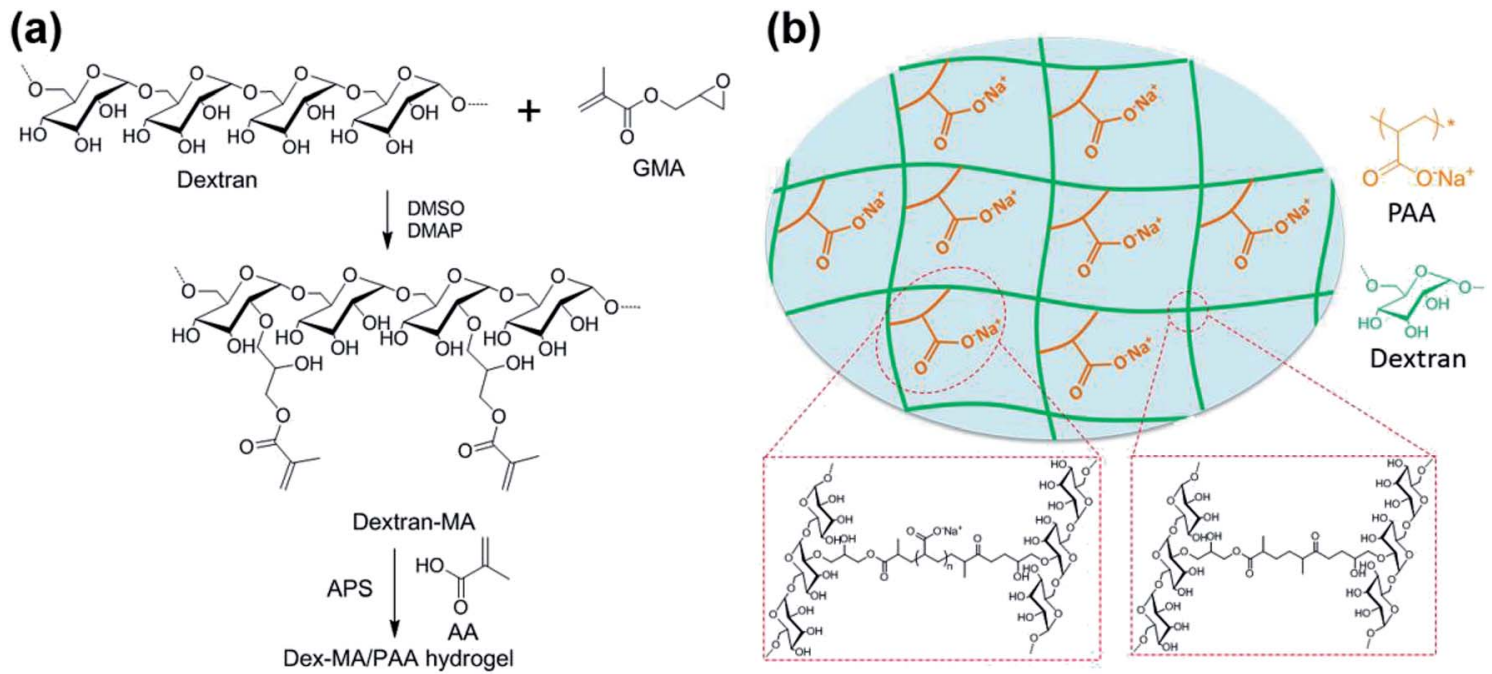

Scheme 1 (a) Synthesis of Dex-MA and Dex-MA/PAA hydrogel and (b) the structure of Dex-MA/PAA hydrogel in sodium salt form.
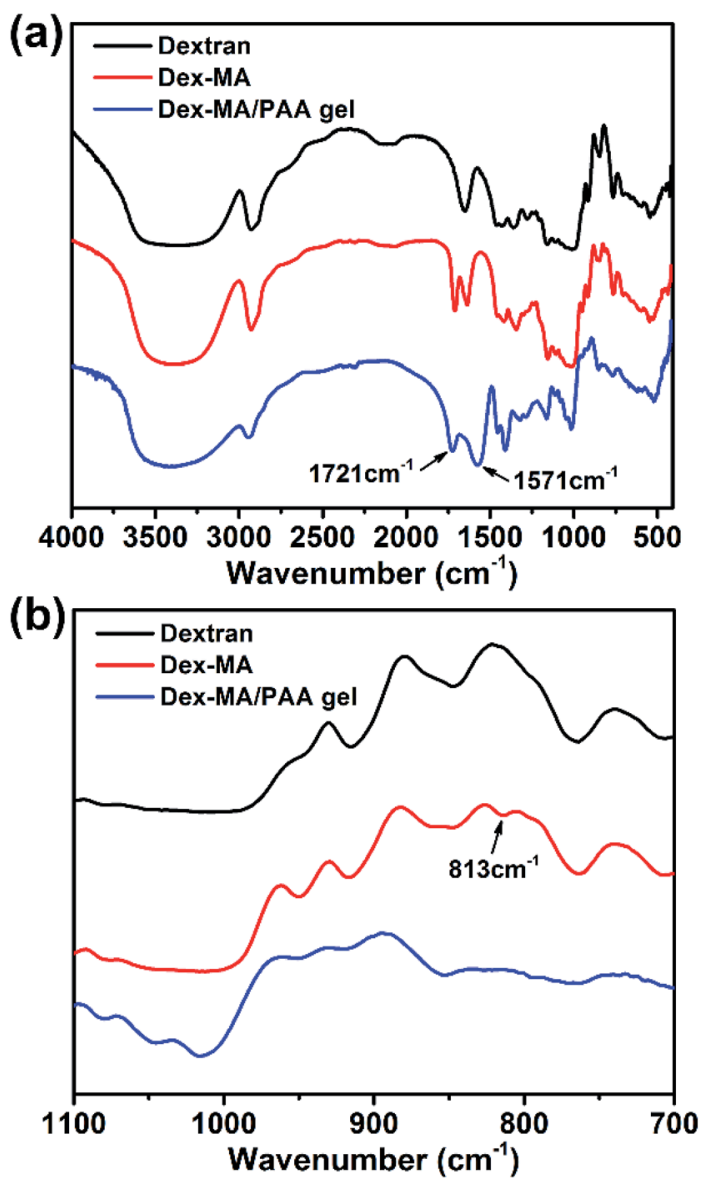

Fig. 2 FT-IR spectra of dextran, Dex-MA and Dex-MA/PAA hydrogel.

high carboxyl group content, the $\mathrm{pH}$ of the solution is one of the most significant factors affecting the surface charge of the DexMA/PAA hydrogel. ${ }^{27}$ So, the $\mathrm{pH}$ at which an adsorbent has zero charge $\left(\mathrm{pH}_{\mathrm{PZC}}\right)$ is an important parameter as it effectively predicts the surface charge at different $\mathrm{pH}$ values. The $\mathrm{pH}_{\mathrm{PZC}}$ for
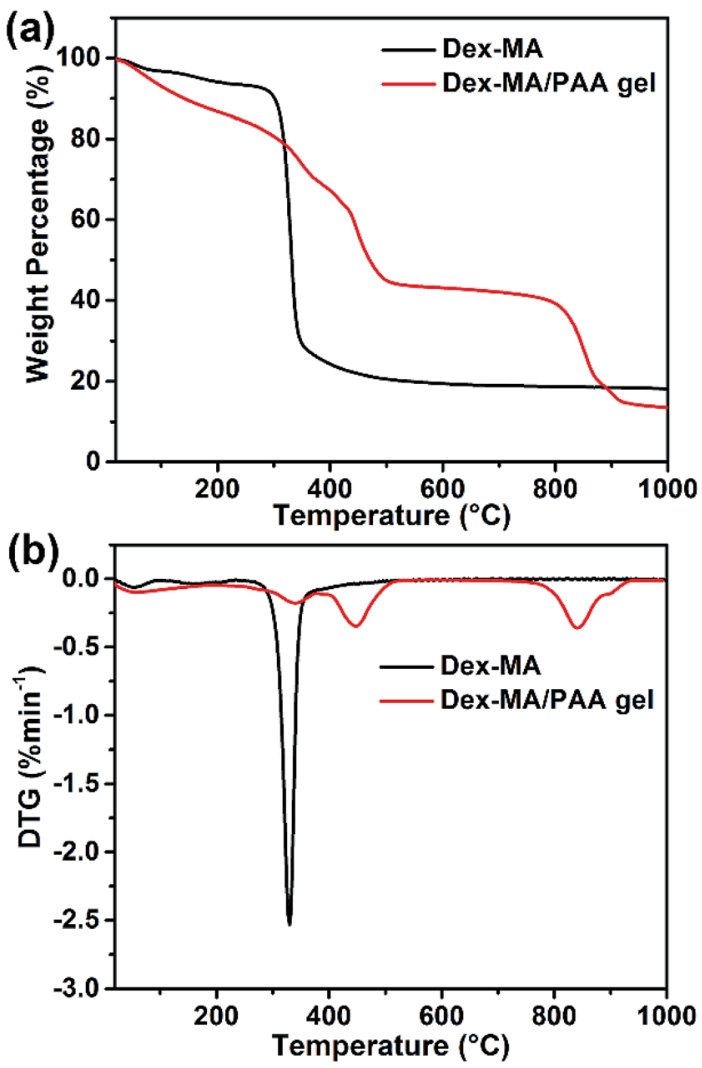

Fig. 3 (a) TGA and (b) DTG curves of Dex-MA and Dex-MA/PAA hydrogel.

the Dex-MA/PAA hydrogel adsorbent was determined to be 6.6, as shown in Fig. S2. $\dagger$ All of the Dex-MA/PAA carboxyl groups were protonated at $\mathrm{pH}<6.6$ but become increasingly deprotonated at $\mathrm{pH}>6.6$ such that the adsorbent surface is increasingly negatively charged as required for the adsorption of cationic dyes. ${ }^{31,32}$ 

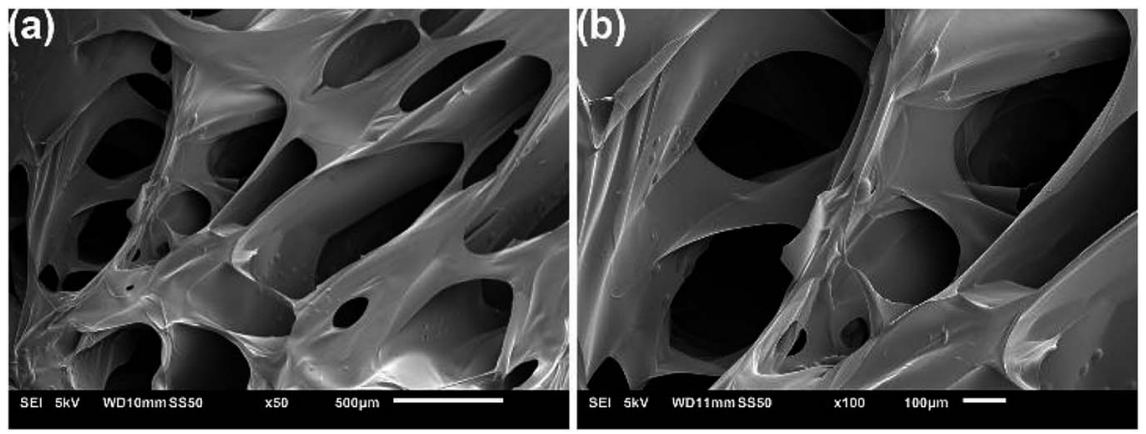

Fig. 4 SEM images of the fracture surface of the freeze-dried Dex-MA/PAA hydrogel at two magnifications.

The variation of the dye removal efficiency of the Dex-MA/ PAA hydrogel adsorbent at $\mathrm{pH}_{\text {initial }}$ ranging from 2 to 10 for $\mathrm{MB}$ and $\mathrm{CV}$ is shown in Fig. $5 \mathrm{a}$. At $\mathrm{pH}_{\text {initial }} 2.0$ the removal efficiency for $\mathrm{MB}$ and $\mathrm{CV}$ were $47.8 \%$ and $56.9 \%$, respectively. When the $\mathrm{pH}_{\text {initial }}$ slightly increased to 3.0 , the removal efficiency for both dyes were higher than $96 \%$. However, further increases in $\mathrm{pH}_{\text {initial }}$ to 10.0 produced no additional increase in the removal efficiency for the dyes. Overall, these data show that the Dex-MA/PAA hydrogel adsorbs MB and CV particularly
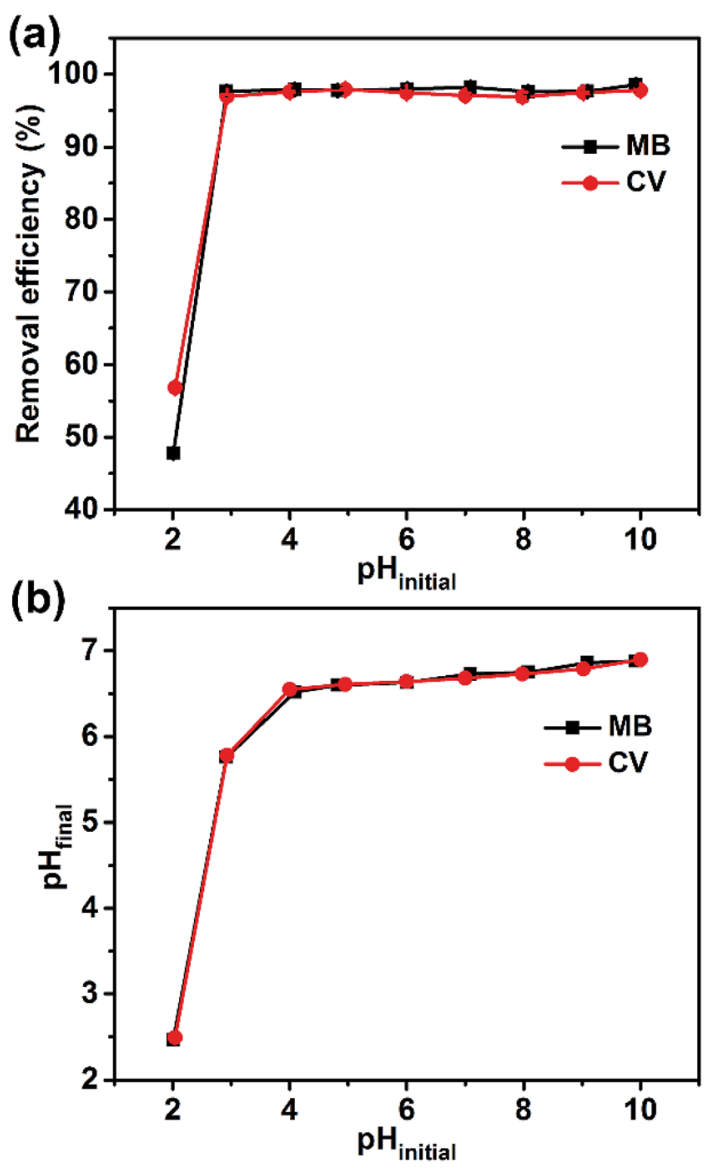

Fig. 5 (a) Effect of initial solution $\mathrm{pH}$ on the removal efficiency by the Dex-MA/PAA hydrogel and (b) finial $\mathrm{pH}$ changes after adding the DexMA/PAA hydrogel. Dex-MA/PAA hydrogel dose: $1 \mathrm{~g} \mathrm{~L}^{-1}$, dye concentration: $50 \mathrm{mg} \mathrm{L}^{-1}$, contact time: $3 \mathrm{~h}$. effectively over the $\mathrm{pH}_{\text {initial }}$ range of 3-10 due to its strong buffer ability.

This dye adsorption pattern coincided with changes from $\mathrm{pH}_{\text {initial }}$ to $\mathrm{pH}_{\text {final }}$, after adding the Dex-MA/PAA hydrogel to the dye solutions as a consequence of variations in the extent of protonation of the carboxylate groups. Thus, there was a larger increase of $\mathrm{pH}_{\text {finial }}$ from $\mathrm{pH}_{\text {initial }}=3$ to 4 , lesser increases from $\mathrm{pH}_{\text {initial }}=4$ to 10 (Fig. $5 \mathrm{~b}$ ). These changes are a consequence of buffering by the Dex-MA/PAA hydrogel centered on $\mathrm{pH}_{\mathrm{PZC}}=6.6$. The adsorption of $\mathrm{MB}$ and $\mathrm{CV}$ in solutions with $\mathrm{pH}_{\text {final }}<\mathrm{pH}_{\mathrm{PZC}}$ in particular indicates that both dyes strongly compete with protons for electrostatic interaction with Dex-MA/PAA carboxylate groups.

\subsection{Effect of $\mathrm{NaCl}$ concentration on dye adsorption}

The differing effects of $\mathrm{NaCl}$ concentration on the absorption of Dex-MA/PAA hydrogel for MB and CV are shown Fig. 6. The removal efficiency of $\mathrm{MB}$ changed from $>97 \%$ to $4.3 \%$ when sodium chloride concentration was increased from 0 to $400 \mathrm{mM}$, and that of CV changed from $>97 \%$ to $43.9 \%$. This is consistent with $\mathrm{Na}^{+}$competitively interacting with the Dex-MA/ PAA carboxylate groups to produce a screening effect which decreases cationic dye adsorption as found in other studies. ${ }^{33,34}$

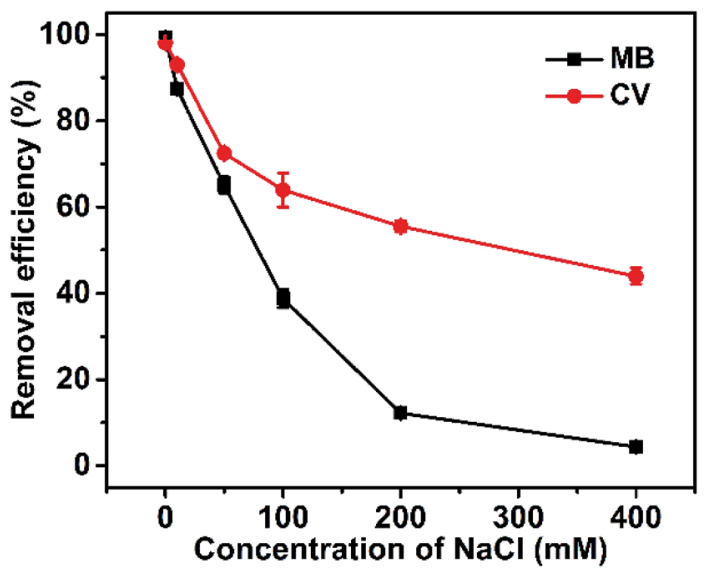

Fig. 6 Effect of $\mathrm{NaCl}$ concentration on removal efficiency of Dex-MA/ PAA hydrogel (Dex-MA/PAA hydrogel dose: $1 \mathrm{~g} \mathrm{~L}^{-1}$, dye concentration: $50 \mathrm{mg} \mathrm{L}^{-1}$, contact time: $3 \mathrm{~h}$, initial $\mathrm{pH}$ 8.0). 


\subsection{Effect of temperature on dye adsorption}

The adsorption of the dyes onto the Dex-MA/PAA hydrogel decreased slightly with increase in temperature from $293 \mathrm{~K}$ to $333 \mathrm{~K}$ as shown by the decreases of $1.3 \%$ and $2.2 \%$ in the removal efficiency for $\mathrm{MB}$ and $\mathrm{CD}$, respectively, in Fig. 7. A similarly small absorption decrease has been reported for $\mathrm{MB}$ adsorption on other adsorbents. ${ }^{15}$

The free energy change, enthalpy change and entropy change for dye adsorption, $\Delta G^{0}, \Delta H^{0}$ and $\Delta S^{0}$, were determined through the following equations:

$$
\begin{gathered}
K_{\mathrm{d}}=\frac{C_{0}-C_{\mathrm{e}}}{C_{\mathrm{e}}} \\
\Delta G^{0}=-R T \ln K_{\mathrm{d}} \\
\Delta G^{0}=\Delta H^{0}-T \Delta S^{0} \\
\ln \left(K_{\mathrm{d}}\right)=\frac{\Delta S^{0}}{R}-\frac{\Delta H^{0}}{R T}
\end{gathered}
$$

where $K_{\mathrm{d}}$ is the equilibrium constant, $C_{0}$ and $C_{\mathrm{e}}$ are the initial and equilibrium dye concentrations $\left(\mathrm{mg} \mathrm{L}^{-1}\right), R$ is the gas constant and $T$ is the temperature (K). Van't Hoff plots of $\ln K_{\mathrm{d}}$ against $1 / T$ shown as insets in Fig. 7 and the $\Delta H^{0}$ and $\Delta S^{0}$ were calculated from the slope $\left(-\Delta H^{0} / R\right)$ and intercept $\left(\Delta S^{0} / R\right)$. The
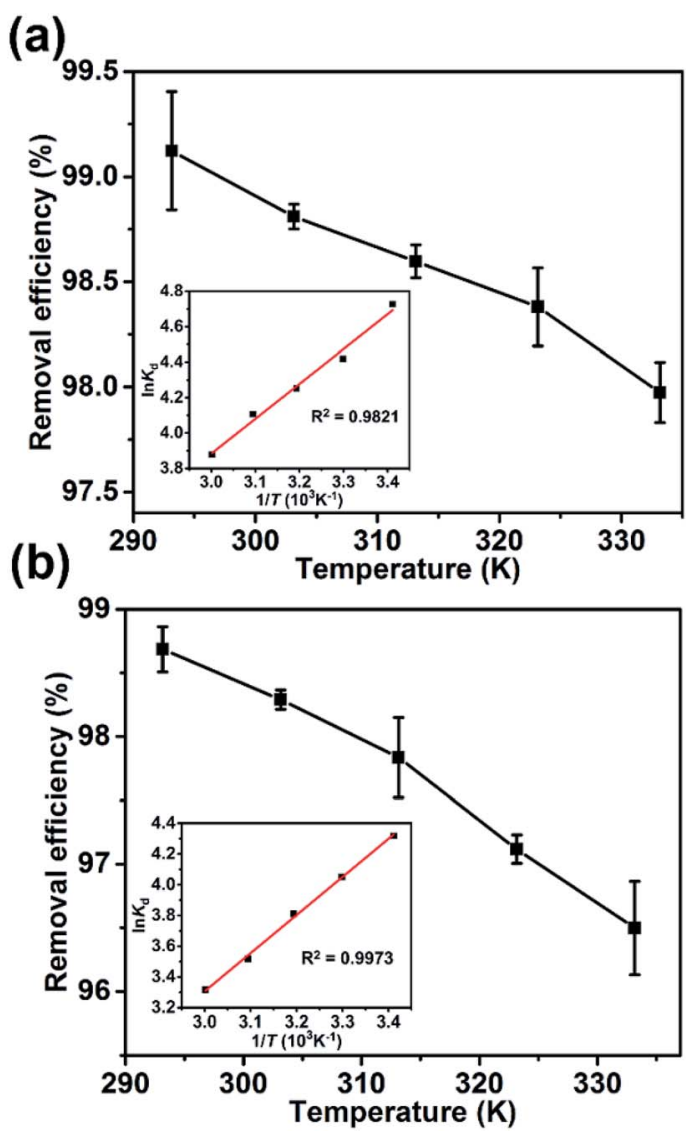

Fig. 7 The effect of temperature on the removal efficiency: (a) MB and (b) CV (inset: Van't Hoff plots for the adsorption of MB and CV on DexMA/PAA). derived thermodynamic parameters appear in Table 1 . For both dyes $\Delta G^{0}$ becomes less negative with increase in temperature consistent with the corresponding decrease in removal efficiency and dye adsorption was a spontaneous process. ${ }^{4,27}$ The negative $\Delta H^{0}$ for adsorption indicated that the dye adsorption process was exothermic, while the negative $\Delta S^{0}$ were indicated the decreased randomness at the solid/liquid interface in the adsorption process..$^{35,36}$

Response surface methodology was also applied for optimization of dyes, and $\mathrm{pH}(A)$, salt concentration $(B)$ and temperature $(C)$ were selected as three factors. The results of variance analyses were shown in Table $\mathrm{S} 3$ and $\mathrm{S} 4 . \dagger$ According to $p$ value, the $A, B, A B, B^{2}$ were significant for removal efficiency of $\mathrm{MB}$, and $A, B, A B, A^{2}, B^{2}$ were significant for removal efficiency of $\mathrm{CV}$, which were also confirmed by $F$ value.

\subsection{Adsorption kinetics}

The adsorption kinetics were characterized by monitored the amount of dye adsorbed against time. Within the first minute the removal efficiencies of $\mathrm{MB}$ and $\mathrm{CV}$ have reached $93.9 \%$ and 86.4\%, respectively (Fig. 8). Thereafter, the removal efficiency of MB and CV leveled off at $\sim 98 \%$ within $\sim 5 \mathrm{~min}$ and $\sim 15 \mathrm{~min}$, respectively, as is seen qualitatively for $\mathrm{MB}$ and $\mathrm{CV}$ solutions before and after adsorption by Dex-MA/PAA in Fig. S6. $\dagger$ This rapid adsorption process is ascribed to the large pore size of the hydrogel networks and their multiple carboxylate groups, indicating the potential usefulness of the Dex-MA/PAA hydrogel as an adsorbent in wastewater treatment.

Generally, the dye adsorption processes are considered to occur in three steps: (1) bulk diffusion of the dye from solution to the adsorbent surface; (2) intra-particle diffusion and electrostatic interactions between the dye and the adsorbent; and (3) the equilibrium state wherein the dye exchanges on and off adsorption sites. ${ }^{26,37}$ To determine the nature of the kinetics of adsorption, the experimental $q_{\mathrm{t}}$ data were fitted to a pseudo-first order (PFO), ${ }^{38}$ a pseudo-second order (PSO), ${ }^{39}$ and the Elovich kinetic model, ${ }^{\mathbf{4 0 , 4 1}}$ and then to the intra-particle diffusion model (Fig. 9). ${ }^{28,42}$

For the PFO kinetic model:

$$
q_{t}=q_{\mathrm{e}}\left(1-\mathrm{e}^{-k_{1} t}\right)
$$

For the PSO kinetic model:

Table 1 Thermodynamics parameters for $M B$ and $C V$ adsorption on Dex-MA/PAA at different temperatures

\begin{tabular}{lll}
\hline Parameters & & $\Delta G^{0}\left(\mathrm{~kJ} \mathrm{~mol}^{-1}\right)$ of dyes \\
\cline { 2 - 3 }$T(\mathrm{~K})$ & $\mathrm{MB}$ & $\mathrm{CV}$ \\
\hline 293 & -11.52 & -10.52 \\
303 & -11.14 & -10.21 \\
313 & -11.07 & -9.92 \\
323 & -11.03 & -9.45 \\
333 & -10.74 & -9.19 \\
$\Delta H^{0}\left(\mathrm{~kJ} \mathrm{~mol}^{-1}\right)$ & -16.38 & -20.61 \\
$\Delta S^{0}\left(\mathrm{~J} \mathrm{~mol}^{-1} \mathrm{~K}^{-1}\right)$ & -16.84 & -34.34
\end{tabular}




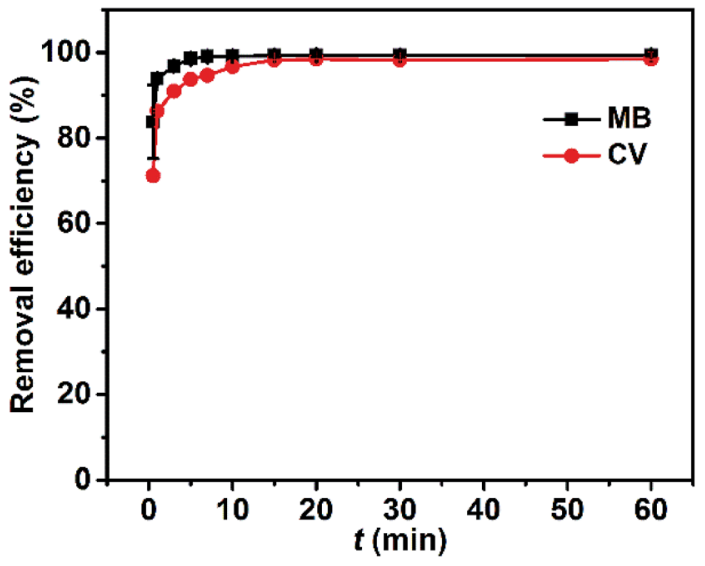

Fig. 8 Effect of contact time, $t$, on the dye removal efficiency. Hydrogel adsorbent dose: $1 \mathrm{~g} \mathrm{~L}^{-1}$, dye concentration: $50 \mathrm{mg} \mathrm{L}^{-1}$, $\mathrm{pH}_{\text {initial }}$ 8.0.

$$
q_{t}=\frac{k_{2} q_{\mathrm{e}}^{2} t}{1+k_{2} q_{\mathrm{e}} t}
$$

where $q_{t}\left(\mathrm{mg} \mathrm{g}^{-1}\right)$ is the adsorption capacity at time $t(\mathrm{~min})$, and $q_{\mathrm{e}}\left(\mathrm{mg} \mathrm{g}^{-1}\right)$ is the equilibrium adsorption capacity; $k_{1}\left(\mathrm{~min}^{-1}\right)$ and $k_{2}\left(\mathrm{~g} \mathrm{mg}^{-1} \mathrm{~min}^{-1}\right)$ are the adsorption rate constant for the pseudo-first order and pseudo-second order kinetics models, respectively.
The Elovich kinetic model:

$$
q_{t}=\frac{1}{\beta} \ln (\alpha \beta)+\frac{1}{\beta} \ln t
$$

where $\alpha\left(\mathrm{mg} \mathrm{g}^{-1} \mathrm{~min}^{-1}\right)$ is the adsorption rate constant and $\beta$ ( $\mathrm{g}$ $\mathrm{mg}^{-1}$ ) is the desorption rate constant.

The intra-particle diffusion model:

$$
q_{t}=k_{\mathrm{di}} t^{0.5}+C_{\mathrm{i}}
$$

where $k_{\mathrm{di}}\left(\mathrm{mg} \mathrm{g}^{-1} \min ^{-0.5}\right)$ is the intra-particle diffusion rate constant, $t^{0.5}\left(\mathrm{~min}^{-0.5}\right)$ is the square root of time, and $C_{\mathrm{i}}(\mathrm{mg}$ $\mathrm{g}^{-1}$ ) is the intercept related to the resistance to diffusion.

The best fits of the four kinetic models to the experimental data are shown in Fig. 9 and the derived kinetic parameters and determination coefficients $\left(R^{2}\right)$ appear in Table 2 . It is seen from Fig. 9a and b that the PSO kinetic model best fits experimental data, which is consistent with the high $R^{2}$ values and the theoretical adsorption capacities $\left(q_{\mathrm{e}(\mathrm{cal})}\right)$ calculated from the PSO model being comparable to the experimental values $\left(q_{\text {e(exp })}\right)$ (Table 2). This implies that the adsorption rate is controlled by chemisorption due to electron sharing or exchange between the dyes and the Dex-MA/PAA hydrogel. ${ }^{\mathbf{4 0 , 4 3 , 4 4}}$

The fitting plots for the intra-particle diffusion model for the adsorption of $\mathrm{MB}$ and $\mathrm{CV}$ were displayed in Fig. 9c and d. The experimental data for $\mathrm{MB}$ and $\mathrm{CV}$ adsorption separate into three linear regions indicative of a three-stage adsorption process. It
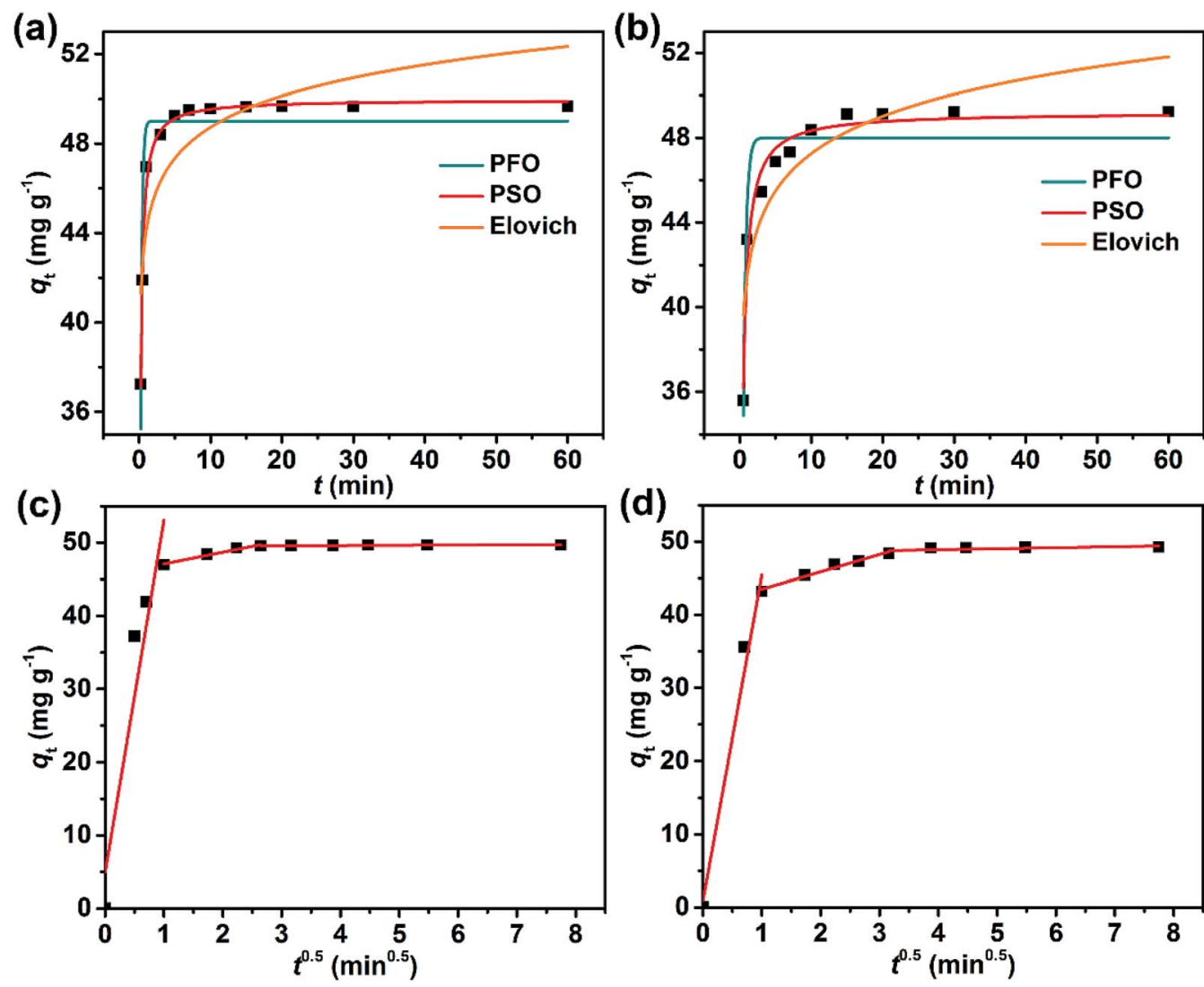

Fig. 9 Dye adsorption on Dex-MA/PAA as a function of time: pseudo-first order (PFO), pseudo-second order (PSO) and Elovich kinetic plots of (a) MB and (b) CV; intra-particle diffusion kinetic plots of (c) MB and (d) CV. 
Table 2 Parameters for pseudo-first order, pseudo-second order and Elovich kinetic models, and intra-particles diffusion model for MB and CV adsorption

\begin{tabular}{|c|c|c|c|}
\hline & \multirow[b]{2}{*}{ Parameter } & \multicolumn{2}{|c|}{ Adsorbing dye } \\
\hline & & MB & $\mathrm{CV}$ \\
\hline \multirow[t]{3}{*}{ Pseudo-first order } & $q_{\mathrm{e}(\mathrm{cal})}$ & 49.0 & 48.0 \\
\hline & $k_{1}$ & 5.08 & 2.60 \\
\hline & $R^{2}$ & 0.8664 & 0.8912 \\
\hline \multirow[t]{3}{*}{ Pseudo-second order } & $q_{\mathrm{e}(\mathrm{cal})}$ & 49.9 & 49.2 \\
\hline & $k_{2}$ & 0.23 & 0.11 \\
\hline & $R^{2}$ & 0.9896 & 0.9666 \\
\hline \multirow[t]{3}{*}{ Elovich } & $\alpha\left(\times 10^{9}\right)$ & 6.63 & 0.03 \\
\hline & $\beta$ & 0.50 & 0.40 \\
\hline & $R^{2}$ & 0.6997 & 0.7716 \\
\hline \multicolumn{4}{|l|}{ Intra-particle diffusion } \\
\hline \multirow[t]{3}{*}{ Stage 1} & $k_{\mathrm{d} 1}$ & 48.2 & 44.5 \\
\hline & $C_{1}$ & 4.95 & 0.93 \\
\hline & $R^{2}$ & 0.8491 & 0.9698 \\
\hline \multirow[t]{3}{*}{ Stage 2} & $k_{\mathrm{d} 2}$ & 1.60 & 2.37 \\
\hline & $C_{2}$ & 45.5 & 41.1 \\
\hline & $R^{2}$ & 0.9528 & 0.9661 \\
\hline \multirow[t]{3}{*}{ Stage 3} & $k_{\mathrm{d} 3}$ & 0.028 & 0.032 \\
\hline & $C_{3}$ & 49.5 & 49.0 \\
\hline & $R^{2}$ & 0.5653 & 0.7519 \\
\hline
\end{tabular}

is seen from Table 2 that the diffusion rate constants for $\mathrm{MB}$ and $\mathrm{CV}$ for each step follows the order of: $k_{\mathrm{d} 1}>k_{\mathrm{d} 2}>k_{\mathrm{d} 3}$, while the intercept $C$ follows the order of: $C_{1}<C_{2}<C_{3}$ and provides the information about the thickness of the boundary layer or resistance to diffusion ${ }^{45}$ The first stage had the highest diffusion constant, $k_{\mathrm{d} 1}$, and lowest intercept, $C_{1}$, consistent with rapid diffusion of the dye from the bulk solution to the Dex-MA/PAA hydrogel surface. In the second stage, adsorption slows as the dye diffuses less rapidly into the pores of the hydrogel (intraparticle diffusion) where it adsorbs through electrostatic interactions. With increasing dye adsorption onto the hydrogel surface, dye adsorption slows further as equilibrium is reached and dye adsorption and desorption reach a kinetic balance in the third stage. Consequently, $k_{\mathrm{d} 3}$ decreases while $C_{3}$ increases. All these observations are consistent with the $\mathrm{MB}$ and $\mathrm{CV}$ adsorption processes occurring in three stages and being partially controlled by intra-particle diffusion. ${ }^{3745}$ The adsorption kinetics at $100 \mathrm{mg} \mathrm{mL}^{-1}$ of dyes were also confirmed and showed similar results (Fig. S7, S8 and Table S5†).

\subsection{Dye adsorption isotherms for Dex-MA/PAA}

The character of the dye adsorption isotherms for the Dex-MA/ PAA hydrogel was determined from the equilibrium $q_{\mathrm{e}}$ and $C_{\mathrm{e}}$ at different initial concentration of dyes. The variations of $q_{\mathrm{e}}$ with $C_{\mathrm{i}}$ for MB and $\mathrm{CV}$ are shown in Fig. 10a and b, respectively. In both cases $q_{\mathrm{e}}$ increased linearly for most of the $C_{\mathrm{i}}$ range before reaching a plateau at $1800 \mathrm{mg} \mathrm{L}^{-1}$ for $\mathrm{MB}$ and $2300 \mathrm{mg} \mathrm{L}^{-1}$ for CV consistent with saturation of the Dex-MA/PAA carboxylate sites. The $q_{\mathrm{e}}$ at saturation were $1984 \mathrm{mg} \mathrm{g}^{-1}$ for MB and $2405 \mathrm{mg}$ $\mathrm{g}^{-1}$ for CV.
These adsorption data were fitted to four adsorption isotherm models expressed as follows:

The Freundlich isotherm model:

$$
q_{\mathrm{e}}=k_{\mathrm{F}} C_{\mathrm{e}}^{\frac{1}{n_{\mathrm{F}}}}
$$

where $k_{\mathrm{F}}\left(\mathrm{mg} \mathrm{g}^{-1}\left(\mathrm{~L} \mathrm{mg}^{-1}\right)^{1 / n}\right)$ is the Freundlich isotherm constant and $n_{\mathrm{F}}$ (dimensionless) is the heterogeneity factor related to the adsorption. This model assumes adsorption to occur on an energetically heterogeneous surface. ${ }^{4}$

The Temkin isotherm model:

$$
q_{\mathrm{e}}=\frac{R T}{b_{\mathrm{T}}} \ln \left(k_{\mathrm{T}} C_{\mathrm{e}}\right)
$$

where $R\left(8.314 \mathrm{~J} \mathrm{~K}^{-1} \mathrm{~mol}^{-1}\right)$ is the universal gas constant, $T(\mathrm{~K})$ is the absolute temperature, $b_{\mathrm{T}}$ (dimensionless) is related to the heat of adsorption and $k_{\mathrm{T}}\left(\mathrm{L} \mathrm{mg}^{-1}\right)$ is the Temkin isotherm constant. This model assumes heat adsorption to decrease as surface coverage increases. ${ }^{26}$

The Langmuir isotherm model:

$$
q_{\mathrm{e}}=\frac{q_{\mathrm{m}} k_{\mathrm{L}} C_{\mathrm{e}}}{1+k_{\mathrm{L}} C_{\mathrm{e}}}
$$

where $q_{\mathrm{m}}\left(\mathrm{mg} \mathrm{g}^{-1}\right)$ is the maximum adsorption capacity; $k_{\mathrm{L}}(\mathrm{L}$ $\mathrm{mg}^{-1}$ ) present the adsorption energy. This model assumes that adsorption occurs on a homogeneous monolayer surface. ${ }^{46}$

The Sips isotherm model:

$$
q_{\mathrm{e}}=\frac{q_{\mathrm{m}}\left(k_{\mathrm{S}} C_{\mathrm{e}}\right)^{\frac{1}{n_{\mathrm{S}}}}}{1+\left(k_{\mathrm{S}} C_{\mathrm{e}}\right)^{\frac{1}{n_{\mathrm{S}}}}}
$$

where $k_{\mathrm{S}}\left(\mathrm{L} \mathrm{mg}^{-1}\right)$ is related the adsorption energy and the $n_{\mathrm{S}}$ is the heterogeneity factor related to the adsorption. Besides, the Sips model incorporates both heterogeneity and saturation and effectively combines the Freundlich and Langmuir models. ${ }^{27,47}$

The isotherm parameters calculated through fitting the adsorption data to the four models appear in Table 3, and the best-fit curves for MB and CV adsorption appear in Fig. 10c and d respectively. On the basis of the $R^{2}$ values, the experimental data were best-fitted by the Sips isotherm model. The maximum adsorption capacity $q_{\mathrm{m}(\mathrm{cal})}$ of $\mathrm{MB}\left(1994 \mathrm{mg} \mathrm{g}^{-1}, 6.23 \mathrm{mmol}\right)$ and CV (2390 $\mathrm{mg} \mathrm{g}^{-1}, 5.86 \mathrm{mmol}$ ) calculated through the Sips isotherm model are similar to the experimental maximum adsorption capacities $q_{\mathrm{m}(\exp )}$ (Table 3 ). The calculated $k_{\mathrm{S}}$ of MB $\left(0.12 \mathrm{~L} \mathrm{mg}^{-1}\right)$ was less than that of $\mathrm{CV}\left(0.19 \mathrm{~L} \mathrm{mg}^{-1}\right)$, indicating that $\mathrm{CV}$ has a higher affinity for adsorption by the Dex-MA/PAA hydrogel than MB. The heterogeneity factor, $n_{\mathrm{S}}$ for both $\mathrm{MB}$ (0.40) and CV (0.14) are both significantly less than unity indicating that their adsorption processes are only moderately heterogeneous in nature. ${ }^{47}$

\subsection{Comparison with other polysaccharide based adsorbents}

The maximum adsorption capacities of Dex-MA/PAA hydrogel adsorbent for $\mathrm{MB}$ and $\mathrm{CV}$ are compared with other polysaccharide based adsorbents in Table 4 . On the basis of the $q_{\mathrm{m}}$ data it is seen that the Dex-MA/PAA hydrogel possessed 
(a)
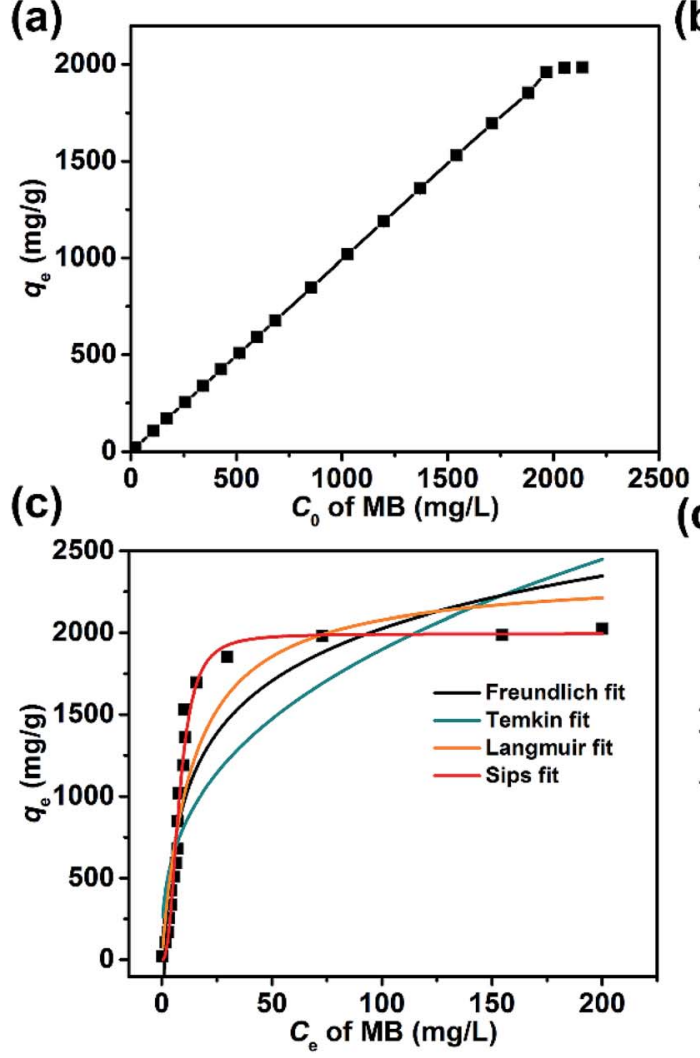

(b)
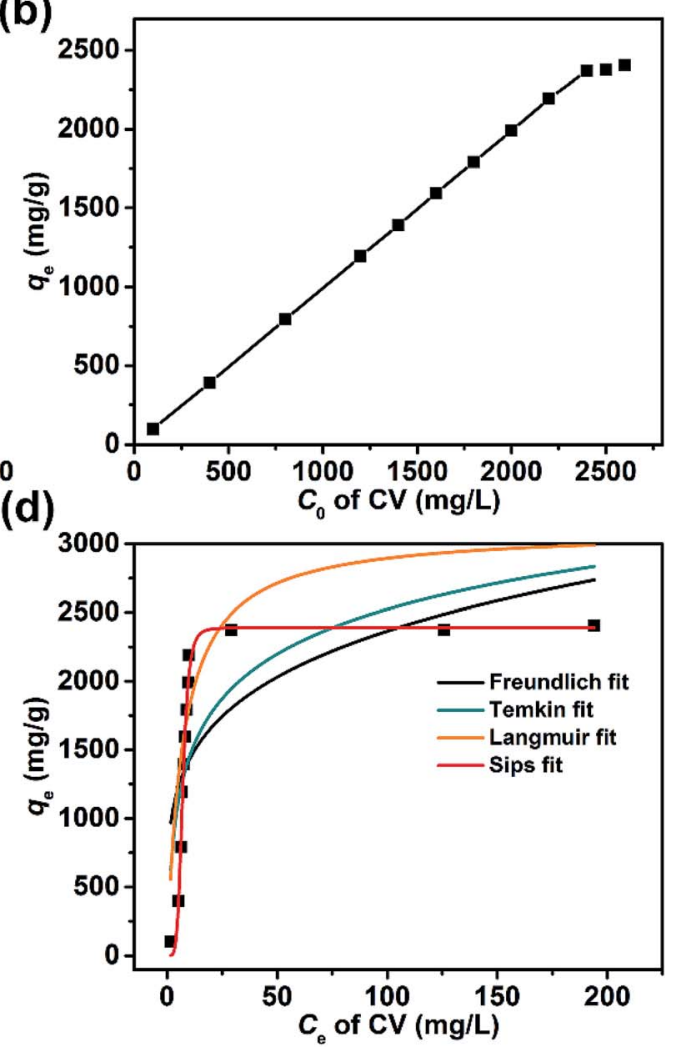

Fig. 10 The variation of the amount of dye adsorbed at equilibrium by Dex-MA/PAA, $q_{\mathrm{e}}$, with initial dye concentrations, $C_{0}$, for (a) MB and (b) CV. The fitting curves for the Freundlich, Temkin, Langmuir and Sips isotherms for (c) MB and (d) CV. Dex-MA/PAA dose: $1 \mathrm{~g} \mathrm{~L}^{-1}, \mathrm{pH}_{\text {initial }} 8.0$.

Table 3 Derived parameters for the Freundlich, Temkin, Langmuir and Sips isotherm models for MB and CV adsorption

\begin{tabular}{|c|c|c|c|}
\hline \multirow[b]{3}{*}{ Isotherm } & \multirow[b]{2}{*}{ Parameters } & \multicolumn{2}{|c|}{ Adsorbing dye } \\
\hline & & \multirow{2}{*}{$\frac{\mathrm{MB}}{1984}$} & \multirow{2}{*}{$\frac{C V}{2405}$} \\
\hline & $q_{\mathrm{e}(\exp )}\left(\mathrm{mg} \mathrm{g}^{-1}\right)$ & & \\
\hline \multirow[t]{3}{*}{ Freundlich } & $k_{\mathrm{F}}$ & 350 & 856 \\
\hline & $n_{\mathrm{F}}$ & 2.72 & 4.53 \\
\hline & $R^{2}$ & 0.6992 & 0.4734 \\
\hline \multirow[t]{3}{*}{ Temkin } & $k_{\mathrm{T}}$ & 0.80 & 2.13 \\
\hline & $b_{\mathrm{T}}$ & 5.27 & 5.18 \\
\hline & $R^{2}$ & 0.8415 & 0.5915 \\
\hline \multirow[t]{3}{*}{ Langmuir } & $q_{\mathrm{m}(\max )}$ & 2364 & 3380 \\
\hline & $k_{\mathrm{L}}$ & 0.073 & 0.10 \\
\hline & $R^{2}$ & 0.8838 & 0.5730 \\
\hline \multirow[t]{4}{*}{ Sips } & $q_{\mathrm{m}(\max )}$ & 1994 & 2390 \\
\hline & $k_{\mathrm{S}}$ & 0.12 & 0.19 \\
\hline & $n_{\mathrm{S}}$ & 0.40 & 0.14 \\
\hline & $R^{2}$ & 0.9861 & 0.9838 \\
\hline
\end{tabular}

a relative high adsorption capacity for $\mathrm{MB}$ and an even higher one for CV by comparison with other adsorbents. These results indicated that the Dex-MA/PAA hydrogel can be recognized as a promising adsorbent for removing the cationic dyes.

The performance of Dex-MA/PAA hydrogel in the presence of both cationic dyes were also measured (MB $50 \mathrm{mg} \mathrm{L}^{-1}, \mathrm{CV}$ $\left.50 \mathrm{mg} \mathrm{L}^{-1}\right)$. The results showed that both removal efficiency of MB and CV were higher than 98\% due to the high adsorption capacity of Dex-MA/PAA hydrogel (Fig. S9†). Besides, humic acid is one of the natural organic matter (NOM) existing in the river and soil. Several studies have shown that the presence of humic acid can significant affect the adsorption of organic pollutant from their aqueous solutions, and the pollutants will gradually accumulate in the river and soil. ${ }^{\mathbf{4 7 8}}$ Here, humic acid was mixed with $\mathrm{MB}$ and $\mathrm{CV}$ and the removal efficiency was investigated under Dex-MA/PAA hydrogel. As shown in Fig. S10, $\dagger$ the removal efficiency of $\mathrm{MB}$ and $\mathrm{CV}$ were nearly invariant even at $50 \mathrm{mg} \mathrm{\textrm {L } ^ { - 1 }}$ of humic acid, and the Dex-MA/PAA hydrogel presented strong adsorption ability to $\mathrm{MB}$ and $\mathrm{CV}$. This was probably because the humic acid could not compete with MB and CV onto adsorption sites. Meanwhile, the $\mathrm{pH}$ of the solution was stable due to the excellent buffer ability, which decrease the influence of humic acid.

\subsection{Dye desorption and reuse studies}

The regeneration of an adsorbent is crucial for its practical applications. As shown in Fig. 11, five adsorption/desorption cycles were performed with the Dex-MA/PAA hydrogel to evaluate its reusability. The removal efficiencies for MB and CV were $>95 \%$ and showed very small variations over the five cycles, demonstrating the excellent recycling performance and stability of the Dex-MA/PAA hydrogel. 
Table 4 Maximum adsorption capacities of polysaccharide based adsorbents

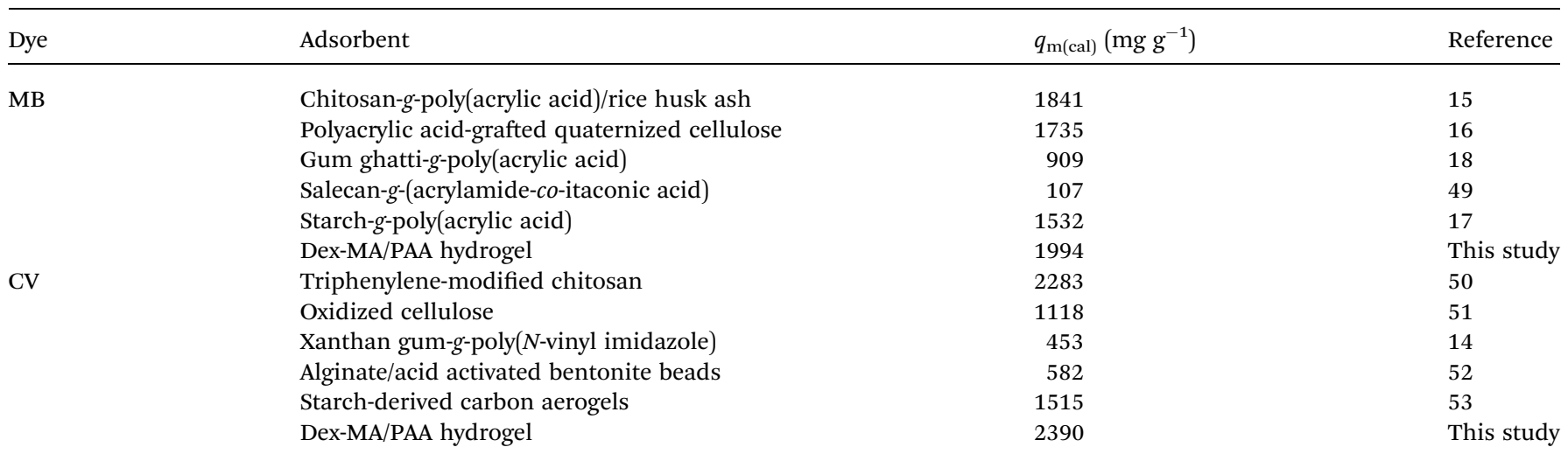
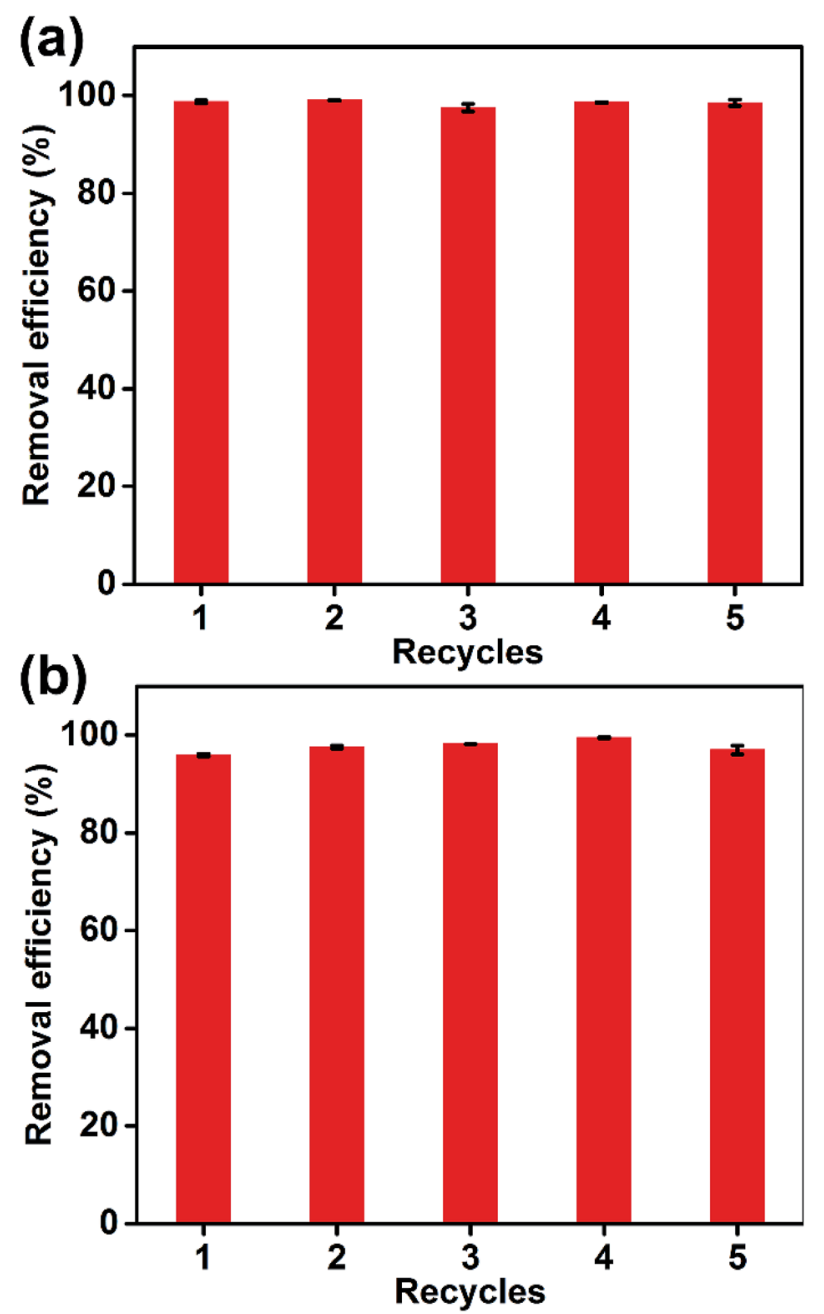

Fig. 11 Removal efficiencies for (a) MB and (b) CV were $>95 \%$ after five Dex-MA/PAA hydrogel adsorption/desorption cycles. Dex-MA/PAA hydrogel dose: $1 \mathrm{~g} \mathrm{~L}^{-1}$, dye concentration: $50 \mathrm{mg} \mathrm{L}^{-1}, \mathrm{pH}_{\text {initial }}$ 8.0.

\section{Conclusions}

In this study, the Dex-MA/PAA hydrogel adsorbent was prepared by using glycidyl methacrylate modified dextran (Dex-MA) as the biocompatible cross-linker and acrylic acid as the functional group. Dex-MA/PAA hydrogel presented high removal efficiency on Methylene Blue (MB) and Crystal Violet (CV) over a wide range of $\mathrm{pH}(3-10)$ due to the strong buffer ability. The adsorbent presented fast adsorption rate with short equilibrium for MB (5 min) and CV (15 min). Besides, the equilibrium data were well simulated by Sips model, and the calculated maximum adsorption capacity was $1994 \mathrm{mg} \mathrm{g}^{-1}$ for MB and $2390 \mathrm{mg} \mathrm{g}^{-1}$ for $\mathrm{CV}$, which were higher than other polysaccharides based adsorbents. Moreover, the adsorbents were regenerated and reused for 5 times without a significant efficiency loss. These data show that the Dex-MA/PAA hydrogel is a promising candidate for a use as an efficient adsorbent in water treatment.

\section{Conflicts of interest}

There are no conflicts to declare.

\section{Acknowledgements}

This work was supported by the NSFC Grants (51761135128, 51403062, and 51773061) and Key Scientific and Technological Project of Xinjiang Bingtuan (2018AB025), China Scholarship Council (CSC).

\section{References}

1 T. Ngulube, J. R. Gumbo, V. Masindi and A. Maity, J. Environ. Manage., 2017, 191, 35-57.

2 W. S. W. Ngah, L. C. Teong and M. Hanafiah, Carbohydr. Polym., 2011, 83, 1446-1456.

3 A. Kausar, M. Iqbal, A. Javed, K. Aftab, Z. I. H. Nazli, H. N. Bhatti and S. Nouren, J. Mol. Liq., 2018, 256, 395-407.

4 Y. Chen, F. He, Y. Ren, H. Peng and K. Huang, Chem. Eng. J., 2014, 249, 79-92.

5 Y. Zhang, Z.-R. Tang, X. Fu and Y.-J. Xu, ACS Nano, 2010, 4, 7303-7314.

$6 \mathrm{H}$. Sarkka, A. Bhatnagar and M. Sillanpaa, J. Electroanal. Chem., 2015, 754, 46-56.

7 M. Ali, A. Sarkar, M. D. Pandey and S. Pandey, Anal. Sci., 2006, 22, 1051-1053. 
8 Y. Han, Z. Xu and C. Gao, Adv. Funct. Mater., 2013, 23, 36933700.

9 A. K. Verma, R. R. Dash and P. Bhunia, J. Environ. Manage., 2012, 93, 154-168.

10 M. A. M. Salleh, D. K. Mahmoud, W. Karim and A. Idris, Desalination, 2011, 280, 1-13.

11 T. I. Tikhomirova, G. R. Ramazanova and V. V. Apyari, J. Anal. Chem., 2017, 72, 917-934.

12 M. T. Yagub, T. K. Sen, S. Afroze and H. M. Ang, Adv. Colloid Interface Sci., 2014, 209, 172-184.

13 Y. M. Wang, J. Wang, Z. Y. Yuan, H. Y. Han, T. Li, L. Li and X. H. Guo, Colloids Surf., B, 2017, 152, 252-259.

14 R. R. Mohamed, M. H. Abu Elella, M. W. Sabaa and G. R. Saad, Cellulose, 2018, 25, 6513-6529.

15 M. G. Vaz, A. G. B. Pereira, A. R. Fajardo, A. C. N. Azevedo and F. H. A. Rodrigues, Water, Air, Soil Pollut., 2017, 228, 1-14.

16 Y. Wang, C. Zhang, L. Zhao, G. Meng, J. Wu and Z. Liu, Fibers Polym., 2017, 18, 891-899.

17 X. W. Liu and Q. Y. Wei, RSC Adv., 2016, 6, 79853-79858.

18 E. Fosso-Kankeu, H. Mittal, S. B. Mishra and A. K. Mishra, J. Ind. Eng. Chem., 2015, 22, 171-178.

19 M. Naessens, A. Cerdobbel, W. Soetaert and E. J. Vandamme, J. Chem. Technol. Biotechnol., 2005, 80, 845-860.

20 E. Cho, M. N. Tahir, J. M. Choi, H. Kim, J.-H. Yu and S. Jung, Carbohydr. Polym., 2015, 133, 221-228.

21 C. Demirbilek and C. O. Dinc, Carbohydr. Polym., 2012, 90, 1159-1167.

22 E. Cho, M. N. Tahir, H. Kim, J.-H. Yu and S. Jung, RSC Adv., 2015, 5, 34327-34334.

23 Q. Liu, M. Zhao, S. Mytnyk, B. Klemm, K. Zhang, Y. Wang, D. Yan, E. Mendes and J. H. van Esch, Angew. Chem., Int. Ed., 2019, 58, 547-551.

24 H. C. Chiu, Y. F. Lin and Y. H. Hsu, Biomaterials, 2002, 23, 1103-1112.

25 A. Abbadessa, M. M. Blokzijl, V. H. M. Mouser, P. Marica, J. Malda, W. E. Hennink and T. Vermonden, Carbohydr. Polym., 2016, 149, 163-174.

26 Y. Zhou, M. Zhang, X. Hu, X. Wang, J. Niu and T. Ma, J. Chem. Eng. Data, 2013, 58, 413-421.

27 F. Zhao, E. Repo, D. Yin, Y. Meng, S. Jafari and M. Sillanpää, Environ. Sci. Technol., 2015, 49, 10570-10580.

28 J. Ma, G. Zhou, L. Chu, Y. Liu, C. Liu, S. Luo and Y. Wei, ACS Sustainable Chem. Eng., 2017, 5, 843-851.

29 W. N. E. van Dijk-Wolthuis, O. Franssen, H. Talsma, M. J. van Steenbergen, J. J. Kettenes-van den Bosch and W. E. Hennink, Macromolecules, 1995, 28, 6317-6322.

30 C. J. Yan, T. H. Yang, S. K. Zhu and H. Wu, J. Mater. Chem. B, 2017, 5, 3697-3705.
31 S. Chowdhury and P. Das, Environ. Prog. Sustainable Energy, 2012, 31, 415-425.

32 S. Y. Wang, K. M. Chen, Y. S. Xu, X. J. Yu, W. H. Wang, L. Li and X. H. Guo, Soft Matter, 2013, 9, 11276-11287.

33 H. Mittal, A. Maity and S. S. Ray, Chem. Eng. J., 2015, 279, 166-179.

34 W. Wang, L. Li, K. Henzler, Y. Lu, J. Wang, H. Han, Y. Tian, Y. Wang, Z. Zhou, G. Lotze, T. Narayanan, M. Ballauff and X. Guo, Biomacromolecules, 2017, 18, 1574-1581.

35 V. K. Gupta, A. Mittal, V. Gajbe and J. Mittal, Ind. Eng. Chem. Res., 2006, 45, 1446-1453.

36 Y. Shao, L. Zhou, C. Bao, J. Ma, M. Liu and F. Wang, Chem. Eng. J., 2016, 283, 1127-1136.

37 P. Wu, Z. Cai, H. Jin and Y. Tang, Sci. Total Environ., 2019, 650, 671-678.

38 X. X. Ruan, Y. H. Chen, H. Chen, G. R. Qian and R. L. Frost, Chem. Eng. J., 2016, 297, 295-303.

39 J.-P. Simonin, Chem. Eng. J., 2016, 300, 254-263.

40 K. C. Bedin, A. C. Martins, A. L. Cazetta, O. Pezoti and V. C. Almeida, Chem. Eng. J., 2016, 286, 476-484.

41 X. L. Li, Y. Zhang, L. Y. Jing and X. H. He, Chem. Eng. J., 2016, 292, 326-339.

42 W. Konicki, K. Cendrowski, X. C. Chen and E. Mijowska, Chem. Eng. J., 2013, 228, 824-833.

43 Y. S. Ho and G. McKay, Process Biochem., 1999, 34, 451-465. 44 L. M. Cui, Y. G. Wang, L. Gao, L. H. Hu, L. G. Yan, Q. Wei and B. Du, Chem. Eng. J., 2015, 281, 1-10.

45 Z. Wu, H. Zhong, X. Yuan, H. Wang, L. Wang, X. Chen, G. Zeng and Y. Wu, Water Res., 2014, 67, 330-344.

46 B. Chen, H. N. Zhao, S. J. Chen, F. X. Long, B. Huang, B. Q. Yang and X. J. Pan, Chem. Eng. J., 2019, 356, 69-80.

47 W. Huang, Y. Hu, Y. Li, Y. Zhou, D. Niu, Z. Lei and Z. Zhang, J. Taiwan Inst. Chem. Eng., 2018, 82, 189-197.

48 Z. D. Wen, D. W. Gao, Z. Li and N. Q. Ren, Chem. Eng. J., 2013, 223, 298-303.

49 X. Qi, W. Wei, T. Su, J. Zhang and W. Dong, Carbohydr. Polym., 2018, 195, 368-377.

50 F. Yang, X. Bai, B. Xu and H. Guo, Cellulose, 2013, 20, 895906.

51 L. R. Martins, J. A. V. Rodrigues, O. F. H. Adarme, T. M. S. Melo, L. V. A. Gurgel and L. F. Gil, J. Colloid Interface Sci., 2017, 494, 223-241.

52 A. A. Oladipo and M. Gazi, J. Water Process Eng., 2014, 2, 4352.

53 X. H. Chang, D. R. Chen and X. L. Jiao, Polymer, 2010, 51, 3801-3807. 